\title{
La gestión del recurso malacológico en cazadores-recolectores del Holoceno tardío: los concheros de la costa norte de Santa Cruz (Patagonia, Argentina)
}

\author{
HEIDI HAMMOND \\ CONICET. División Arqueología, Museo de Ciencias Naturales, Facultad de Ciencias Naturales \\ y Museo, Universidad Nacional de La Plata. Paseo del Bosque s/n (1900), La Plata, Argentina. \\ e-mail: heidihammondunlp@gmail.com
}

(Recibido 20 mayo 2016; Revisado 22 octubre 2016; Aceptado 21 noviembre 2016)

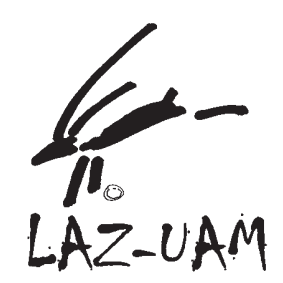

RESUMEN: Los recursos malacológicos que fueron empleados por las sociedades cazadoras-recolectoras generalmente han sido relegados a un segundo plano en los análisis arqueofaunísticos a pesar de la valiosa información que aportan sobre múltiples aspectos de dichas sociedades. En este trabajo se presentan los moluscos asociados con sitios de cazadores-recolectores de la costa norte de la provincia de Santa Cruz en la Patagonia argentina. El objetivo consiste en analizar el papel de los recursos malacológicos en el marco de las estrategias de subsistencia de las sociedades que ocuparon este área durante el Holoceno tardío. Se estudiaron muestras arqueomalacológicas de diez concheros donde se evaluaron la representación y abundancia de las especies, así como la preservación de los restos. Se discuten las zonas de recolección y las posibles estrategias de obtención de las principales especies. Se registraron diferencias biométricas a través del tiempo que apuntarían a un proceso de explotación mantenida donde es posible postular un proceso tenue de intensificación en el uso del recurso durante el Holoceno tardío.

PALABRAS CLAVE: ARQUEOMALACOLOGÍA, CONCHEROS, TAFONOMÍA, HOLOCENO TARDÍO, PATAGONIA ARGENTINA

\begin{abstract}
Molluscs from hunter-gatherer societies have generally given second place in faunal analyses in spite of the fact that these remains provide valuable insights about many aspects of human societies. In this paper the molluscs used by hunter-gatherer groups occupying the northern coast of Santa Cruz province in the Argentinian Patagonia are presented. The aim is to analyze the role these resources played during the late Holocene in the subsistence strategies deployed by people that inhabited the area. Mollusc assemblages from ten shell middens were studied and the species abundances as well as the preservation of the remains evaluated. Harvesting places and strategies deployed, along with the biometry of the most common species are evaluated. Biometric differences over time reveal a process of recurrent exploitation that hint at a slight intensification of resource use during the late Holocene.
\end{abstract}

KEYWORDS: ARCHAEOMALACOLOGY, SHELL MIDDENS, TAPHONOMY, LATE HOLOCENE, PATAGONIA ARGENTINA 


\section{INTRODUCCIÓN}

El área de estudio de la costa norte de Santa Cruz (CNSC) abarca el territorio de litoral patagónico comprendido entre el límite de las provincias de Chubut y Santa Cruz al norte, y la localidad Bahía Laura, al sur; a lo largo de aproximadamente 420 km (Castro et al., 2003; Figura 1). A partir de las investigaciones arqueológicas desarrolladas en el área se registró una gran cantidad de concheros los cuales implican distintas clases de arqueosedimentos, entre los que predominan conchas y proporciones variables de matriz sedimentaria, en asociación con restos óseos de vertebrados, artefactos líticos y carbón vegetal.

El uso alimentario de los recursos malacológicos en la CNSC se ha constatado en concheros de comienzos del Holoceno medio (Ambrústolo et al., 2011; Zubimendi et al., 2015). Sin embargo, durante el Holoceno tardío se registra un aumento en la cantidad de concheros que evidenciaría la explotación sistemática del recurso malacológico durante este momento (Zubimendi, 2012; Hammond et al., 2013; Hammond, 2015; Zubimendi et $a l ., 2015$; entre otros). Aunque en el área de estudio existen estudios zooarqueológicos sobre la explotación tanto de vertebrados como de invertebrados
(Moreno, 2008; Beretta et al., 2011; Zubimendi, 2012; Hammond, 2013; entre otros), las investigaciones arqueomalacológicas deben ser ampliadas a fin de poder caracterizar de manera más acabada la explotación del medio marino, la selección y el procesado de las especies recolectadas y para comprender los procesos de formación de los sitios donde dominan los restos de moluscos.

Con tal objetivo se estudiaron conjuntos arqueomalacológicos procedentes de diez concheros del Holoceno tardío ubicados en un sector del litoral atlántico de la región patagónica argentina (Figura 1). En todos ellos se estudió la composición biológica de los conjuntos, la preservación de los restos, la biometría de las especies mejor representadas validando así mismo evidencias referidas a la estructura de los sitios y a las estrategias de explotación de los moluscos.

\section{CARACTERIZACIÓN AMBIENTAL Y CONDICIONES PALEOECOLÓGICAS}

Los concheros analizados se emplazan en el estuario de la ría Deseado y en localidades arqueológicas del litoral atlántico situadas al sur de la ría

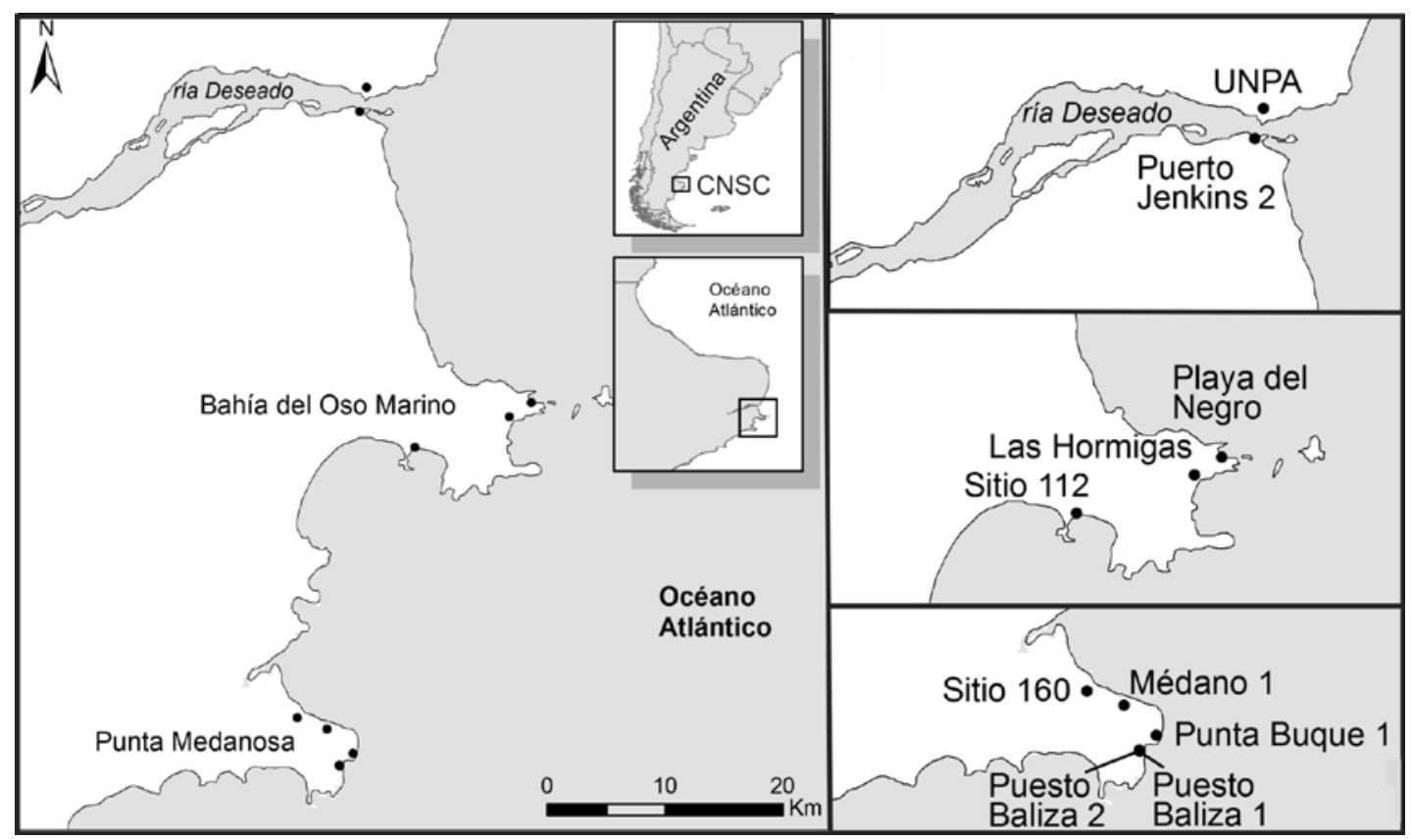

FIGURA 1

Mapa del área de estudio y ubicación de los concheros. 
(Figura 1). La ría Deseado es un estuario natural que presenta una longitud aproximada de $42 \mathrm{~km}$ (Figura 1). En la margen norte del estuario existen diversos cañadones que desembocan en la ría algunos de los cuales presentan evidencias de ocupación humana (Ambrústolo \& Ciampagna, 2015); mientras, en la margen sur, estos cañadones son escasos y no han alcanzado el nivel de base actual (Iantanos, 2004). El sector de costa al sur de la ría Deseado se caracteriza por la abundancia de recursos marinos, especialmente pinnípedos, aves, peces y moluscos (Castro et al., 2003). Presenta amplias plataformas de abrasión, además de sectores de dunas y mantos eólicos sobre terrazas y cordones litorales donde se han identificado numerosos concheros (Castro et al., 2003; Hammond, 2015).

A partir de la datación de depósitos biogénicos ubicados en diferentes niveles de costa a lo largo de Patagonia se estableció que el máximo de la transgresión marina en el Holoceno habría ocurrido hace ca. 7000 años AP (Codignotto et al., 1992; González Bonorino et al., 1999; Rostami et al., 2000). Codignotto et al. (1992) postulan que el máximo nivel del mar durante el Holoceno tuvo lugar en el lapso entre $c a$. 6500-4000 años AP hallándose la costa argentina en continuo ascenso debido a procesos neotectónicos e hidroisostáticos. Estudios de la fauna malacológica realizados en la CNSC sobre muestras del Pleistoceno final, Holoceno, y del litoral moderno, sugieren condiciones similares a las de la Provincia Magallánica actual. Los taxones identificados (particularmente Nacella sp., Siphonaria lessoni, Trophon sp., Acanthina monodon, Brachidontes sp., Protothaca antiqua y Mytilus edulis) representativos del mencionado bloque temporal, indican paleoambientes típicamente litorales, someros, con sustratos predominantemente consolidados, energía considerable y aguas templado-frías o frías, similares a las que presenta el litoral moderno (Aguirre, 2003; Aguirre et al., 2009). A partir de estos antecedentes, a pesar de los cambios ambientales y de las variaciones de la línea de costa, parece que la disponibilidad y la estructura de los recursos malacológicos en el área CNSC no habrían sufrido importantes modificaciones durante el Holoceno.

\section{MATERIALES Y MÉTODOS}

Los análisis se desarrollaron sobre muestras malacológicas procedentes de diez concheros que se distribuyen a lo largo de $40 \mathrm{~km}$ de litoral atlántico (Figura 1). Las excavaciones estratigráficas constaron de sondeos de pequeñas dimensiones $\left(0,25 \mathrm{~m}^{2}\right)$ y en un caso se desarrolló una excavación amplia de 7,25 $\mathrm{m}^{2}$. En la Tabla 1 se presentan las características generales de cada conchero así como las concentraciones arqueomalacológicas según la estratigrafía. La recuperación de los materiales se realizó con tamices con luz de malla de $2 \mathrm{~mm}$ (Claassen, 1998). La totalidad de la base del tamiz fue trasladado al laboratorio, lo que permitió analizar restos muy pequeños (Hammond, 2015).

Para la identificación anatómica y taxonómica se utilizaron fuentes bibliográficas (Castellanos, 1956; Castellanos \& Landoni, 1988; Aguirre \& Farinati, 2000; Aguirre, 2003; Gordillo, 2007; Aguirre et al., 2009, entre otros), catálogos de moluscos con descripciones y consideraciones acerca de la distribución biogeográfica (Carcelles, 1950; Carcelles \& Williamson, 1951; Núñez Cortés \& Narovsky, 1997; Forcelli, 2000) y colecciones comparativas.

Los caracteres taxonómicos utilizados para la identificación de gasterópodos, incluyen la forma de la concha, las características del ombligo y el estoma, y la ornamentación. Para los bivalvos, se atendió a la forma de la valva, los atributos de la charnela, el número y disposición de las impresiones musculares y la ornamentación (Moreno Nuño, 1994). Para los poliplacóforos se analizó la forma y ornamentación de la valva (Gordillo, 2007). Los restos de cada especie se clasificaron según su estado de conservación en diferentes categorías, empleando la metodología y terminología sugerida por Gutiérrez Zugasti (2008) y Álvarez Fernández (2009). Para los gasterópodos espiralados contamos con las categorías, ICOM: individuos no fragmentados + IFRA: individuos fragmentados que conservan el ápice + [FAPI: fragmentos apicales o (FEST: zona bucal + FUMB: fragmentos con el final de la columela intacto o con el ombligo completo), el valor que sea mayor]. Para los gasterópodos no espiralados, las categorías incluyen: ICOM: individuos completos + IFRA: individuos fragmentados (con ápice y parte del borde de la concha) + FAPI: fragmentos apicales. En bivalvos se utilizaron: VCOM: valva completa con charnela o umbo + VFRA: valva fragmentada que conserva el umbo o charnela + FCHC: fragmento de umbo o charnela completo, sobre la base del valor más alto por lateralidad. Se tomó como NMI el mayor número de restos atendiendo a los centros de la 


\begin{tabular}{|c|c|c|c|c|c|c|c|c|c|c|c|}
\hline \multicolumn{2}{|c|}{ Variables Corcheros } & UNPA & $\begin{array}{l}\text { Puerto } \\
\text { Jenkins } 2\end{array}$ & $\begin{array}{l}\text { Playa del } \\
\text { Negro }\end{array}$ & $\begin{array}{c}\text { Las } \\
\text { Hormigas }\end{array}$ & Sitio 112 & Sitio 160 & Médano 1 & $\begin{array}{c}\text { Punta } \\
\text { Buque 1 }\end{array}$ & $\begin{array}{l}\text { Puesto } \\
\text { Baliza 2 }\end{array}$ & $\begin{array}{l}\text { Puesto } \\
\text { Baliza 2 }\end{array}$ \\
\hline \multicolumn{2}{|c|}{$\begin{array}{l}\text { Emplazamiento } \\
\text { geomorfológico }\end{array}$} & $\begin{array}{l}\text { Cordón } \\
\text { litoral }\end{array}$ & $\begin{array}{l}\text { Cordón } \\
\text { litoral }\end{array}$ & $\begin{array}{l}\text { Planicie } \\
\text { de mareas } \\
\text { inactiva }\end{array}$ & $\begin{array}{l}\text { Manto } \\
\text { eólico }\end{array}$ & $\begin{array}{l}\text { Manto } \\
\text { eólico }\end{array}$ & Duna & Duna & Duna & $\begin{array}{l}\text { Planicie } \\
\text { de mareas } \\
\text { inactiva }\end{array}$ & $\begin{array}{l}\text { Planicie } \\
\text { de mareas } \\
\text { inactiva }\end{array}$ \\
\hline \multicolumn{2}{|c|}{ Superficie excavada $\mathrm{m}^{2}$} & 7,25 & 0,5 & 0,5 & 1 & 0,25 & 0,5 & 0,25 & 0,5 & 0,25 & 0,5 \\
\hline \multicolumn{2}{|c|}{ Fechado radiocarbónico } & $\begin{array}{l}690 \pm 70 \mathrm{AP} \\
(\mathrm{LP}-2896) \\
970 \pm 50 \mathrm{AP} \\
(\mathrm{LP}-2891)\end{array}$ & $\begin{array}{l}690 \pm 60 \mathrm{AP} \\
(\mathrm{LP}-2603)\end{array}$ & $\begin{array}{l}1450 \pm 60 \mathrm{~A} \\
(\mathrm{LP}-2682)\end{array}$ & $\begin{array}{l}370 \pm 40 A P \\
(\mathrm{LP}-2504)\end{array}$ & $\begin{array}{l}2870 \pm 60 \mathrm{AP} \\
(\mathrm{LP}-2141)\end{array}$ & $\begin{array}{l}370 \pm 50 \mathrm{AP} \\
\text { (LP-2507); } \\
1260 \pm 80 \mathrm{AP} \\
(\mathrm{LP}-3091)\end{array}$ & $\begin{array}{l}2140 \pm 60 \mathrm{AP} \\
(\mathrm{LP}-2501)\end{array}$ & $\begin{array}{l}1070 \pm 60 A P \\
(\text { LP- } 2724) ; \\
1720 \pm 100 A P \\
(\text { LP-3099) }\end{array}$ & - & $\begin{array}{l}1290 \pm 60 \\
\text { AP (LP- } \\
2732)\end{array}$ \\
\hline \multicolumn{2}{|c|}{ Morfología } & $\begin{array}{l}\text { Plano } \\
\text { extendido }\end{array}$ & $\begin{array}{l}\text { Plano } \\
\text { extendido }\end{array}$ & $\begin{array}{l}\text { Plano } \\
\text { extendido }\end{array}$ & Montículo & Montículo & Montículo & Montículo & Montículo & $\begin{array}{l}\text { Plano } \\
\text { extendido }\end{array}$ & $\begin{array}{l}\text { Plano } \\
\text { extendido }\end{array}$ \\
\hline \multirow{5}{*}{ 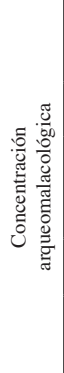 } & Estratigrafía & 1 lente & 1 lente & $\begin{array}{l}\text { Dispersión } \\
\text { de valvas }\end{array}$ & 1 lente & 1 lente & $\begin{array}{l}\text { S1: } 2 \text { lentes } \\
\text { S2: } 1 \text { lente }\end{array}$ & $\begin{array}{l}1 \text { lente } \\
\text { masiva }\end{array}$ & $\begin{array}{l}\text { S1:1 lente } \\
\text { S2:1 lente } \\
\text { masiva }\end{array}$ & $\begin{array}{l}\text { Dispersión } \\
\text { de valvas }\end{array}$ & $\begin{array}{l}\text { Dispersión } \\
\text { de valvas }\end{array}$ \\
\hline & Geometría & Tabular & Tabular & Tabular & Lenticular & Lenticular & Lenticular & Tabular & $\begin{array}{l}\text { S1: Lenticular } \\
\text { S2: Tabular }\end{array}$ & Tabular & Tabular \\
\hline & Fábrica & $\begin{array}{l}\text { Bioclasto } \\
\text { sost./ } \\
\text { Matriz } \\
\text { sost. }\end{array}$ & $\begin{array}{l}\text { Bioclasto } \\
\text { sost. }\end{array}$ & $\begin{array}{l}\text { Matriz } \\
\text { sost. }\end{array}$ & $\begin{array}{l}\text { Bioclasto } \\
\text { sost. }\end{array}$ & $\begin{array}{l}\text { Bioclasto } \\
\text { sost. }\end{array}$ & $\begin{array}{l}\text { Bioclasto } \\
\text { sost./ } \\
\text { Matriz sost. }\end{array}$ & $\begin{array}{l}\text { Bioclasto } \\
\text { sost. }\end{array}$ & $\begin{array}{l}\text { Bioclasto } \\
\text { sost./ } \\
\text { Matriz sost. }\end{array}$ & $\begin{array}{l}\text { Matriz } \\
\text { sost. }\end{array}$ & $\begin{array}{l}\text { Matriz } \\
\text { sost. }\end{array}$ \\
\hline & Textura & Compactada & Compactada & $\begin{array}{l}\text { Compac- } \\
\text { tada }\end{array}$ & Floja & Floja & Floja & Compactada & Compactada & Floja & $\begin{array}{l}\text { Compac- } \\
\text { tada }\end{array}$ \\
\hline & $\begin{array}{l}\text { Densidad de } \\
\text { moluscos } \\
\left(\mathrm{NR} / \mathrm{dm}^{3}\right)\end{array}$ & $\begin{array}{l}\text { Entre 6,5- } \\
27,52\end{array}$ & 37,8 & 14,13 & 15,09 & 31,2 & $\begin{array}{l}\text { S1: } 18,93 \\
\text { S2: } 55,02\end{array}$ & 49,03 & $\begin{array}{l}\text { S1: } 8,28 \\
\text { S2: } 47,68\end{array}$ & 2,95 & $\begin{array}{l}\text { S1: } 11,44 \\
\text { S2: } 17,53\end{array}$ \\
\hline
\end{tabular}

TABLA 1

Características de los concheros analizados en este trabajo. Referencias: S1: Sondeo 1, S2: Sondeo 2.

parasagitalidad (ed., valvas derechas o izquierdas). Los poliplacóforos están compuestos por 8 placas. Los individuos se cuantificaron tomando los valores más altos de placas cefálicas o caudales, o bien el número total de placas intermedias dividido 6 (Gordillo, 2007).

Se calculó la abundancia de los materiales arqueomalacológicos con el empleo de estimadores como el número de restos (NR) y el número mínimo de individuos (NMI). También se estimó la riqueza definida como el número de especies que integran cada uno de los conjuntos (Claassen, 1998).

Para evaluar el estado de conservación de los materiales se consideró la relación entre el NMI total de cada especie y el número de elementos (Verdún, 2014).

Durante la clasificación, se identificaron los agentes y procesos tafonómicos que afectaron a los restos y se evaluaron las condiciones de preservación. En elementos completos y fragmentos identificables de las cuatro especies principales representadas en los conjuntos. Especialmente se examinó la preservación del periostraco, signos de corrosión, abrasión, fragmentación, bioerosión (incrustaciones y perforaciones), alteración térmica, deformación, roturas y/o signos de impacto en conchas de Nacella magellanica (en conchas completas) así como la conservación del color original (Hammond, 2013, 2015).
Todas las piezas de las especies dominantes se incluyeron en el análisis biométrico. Para ello se empleó un calibre digital. Se tomaron las medidas de Nacella magellanica (lapa), Aulacomya atra (cholga), Mytilus edulis (mejillón) y Perumytilus purpuratus (mejillón). En el caso de Nacella, se toma la medida del diámetro máximo de la base de la concha. Para los mitílidos, se mide desde el umbo hasta el extremo distal de la valva. El tamaño de la valva está relacionado con la edad del animal, el microambiente en el que se desarrolló, y el ritmo de crecimiento ontogenético, el cual decrece a medida que aumenta la edad (Claassen, 1998).

\section{RESULTADOS}

\section{Composición arqueomalacológica}

En la Tabla 2 se presenta el NMI de restos malacológicos identificados para cada una de las excavaciones. Se reconocen tres grandes conjuntos de moluscos: gasterópodos, bivalvos y poliplacóforos. La mayoría de los restos se identificaron a nivel específico, sin embargo algunos sólo pudieron ser determinados a nivel de género, familia o incluso de clase. El total identificado en 


\begin{tabular}{|c|c|c|c|c|c|c|c|c|c|c|c|c|c|c|}
\hline \multirow{2}{*}{ Moluscos } & & \multirow{2}{*}{$\stackrel{\overleftarrow{Z}}{\underline{S}}$} & \multirow{2}{*}{ 总 } & \multirow{2}{*}{ 造 } & \multirow{2}{*}{ 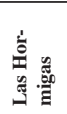 } & \multirow{2}{*}{ 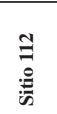 } & \multicolumn{2}{|c|}{ 言点 } & \multirow{2}{*}{ 㲵 } & \multicolumn{2}{|c|}{ 吾咅 } & \multirow{2}{*}{ 㺼 } & \multicolumn{2}{|c|}{ 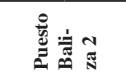 } \\
\hline & & & & & & & S1 & S2 & & S1 & S2 & & S1 & S2 \\
\hline \multicolumn{15}{|c|}{ Cl. Gastropoda } \\
\hline Nacella magellanica & $\begin{array}{l}\mathrm{N} \\
\%\end{array}$ & $\begin{array}{l}2683 \\
40,5\end{array}$ & $\begin{array}{l}2440 \\
69,2\end{array}$ & $\begin{array}{l}811 \\
\mathbf{3 8 , 3}\end{array}$ & $\begin{array}{l}509 \\
18,9\end{array}$ & $\begin{array}{l}35 \\
5,8\end{array}$ & $\begin{array}{l}71 \\
6,8\end{array}$ & $\begin{array}{l}57 \\
6,8\end{array}$ & $\begin{array}{l}229 \\
8,1\end{array}$ & $\begin{array}{l}\mathbf{1 8 5} \\
\mathbf{5 2 , 7}\end{array}$ & $\begin{array}{c}1628 \\
49\end{array}$ & $\begin{array}{l}104 \\
45\end{array}$ & $\begin{array}{l}306 \\
40,5\end{array}$ & $\begin{array}{l}459 \\
37,6\end{array}$ \\
\hline Nacella mytilina & $\begin{array}{l}\mathrm{N} \\
\%\end{array}$ & $\begin{array}{l}1 \\
0\end{array}$ & - & - & - & - & - & - & - & - & - & - & - & - \\
\hline Crepipatella dilatata & $\begin{array}{l}\mathrm{N} \\
\%\end{array}$ & $\begin{array}{l}112 \\
1,7 \\
\end{array}$ & $\begin{array}{r}94 \\
2,7 \\
\end{array}$ & $\begin{array}{r}75 \\
3,5 \\
\end{array}$ & $\begin{array}{r}72 \\
2,8 \\
\end{array}$ & $\begin{array}{c}4 \\
0,7 \\
\end{array}$ & $\begin{array}{l}160 \\
15,3 \\
\end{array}$ & $\begin{array}{c}334 \\
40 \\
\end{array}$ & $\begin{array}{l}511 \\
18,1 \\
\end{array}$ & $\begin{array}{l}31 \\
8,8 \\
\end{array}$ & $\begin{array}{l}178 \\
5,4 \\
\end{array}$ & $\begin{array}{l}12 \\
5,2 \\
\end{array}$ & $\begin{array}{l}31 \\
4,1 \\
\end{array}$ & $\begin{array}{r}59 \\
4,8 \\
\end{array}$ \\
\hline Trochita Pileus & $\begin{array}{l}\mathrm{N} \\
\%\end{array}$ & $\begin{array}{l}1 \\
0\end{array}$ & - & - & - & - & - & - & - & - & - & - & - & - \\
\hline Pareuthria lumbea & $\begin{array}{l}\mathrm{N} \\
\%\end{array}$ & $\begin{array}{l}79 \\
1,2 \\
\end{array}$ & $\begin{array}{c}2 \\
0,1 \\
\end{array}$ & $\begin{array}{l}29 \\
1,4 \\
\end{array}$ & $\begin{array}{c}7 \\
0,3 \\
\end{array}$ & $\begin{array}{c}2 \\
0,4 \\
\end{array}$ & $\begin{array}{c}1 \\
0,1\end{array}$ & $\begin{array}{c}5 \\
0,6 \\
\end{array}$ & $\begin{array}{c}17 \\
0,6\end{array}$ & $\begin{array}{c}3 \\
0,8 \\
\end{array}$ & $\begin{array}{c}3 \\
0,1\end{array}$ & $\begin{array}{c}1 \\
0,4 \\
\end{array}$ & $\begin{array}{c}1 \\
0,1 \\
\end{array}$ & $\begin{array}{l}10 \\
0,8 \\
\end{array}$ \\
\hline Adelomelon sp. & $\begin{array}{l}\mathrm{N} \\
\%\end{array}$ & $\begin{array}{l}2 \\
0\end{array}$ & $\begin{array}{l}1 \\
0\end{array}$ & - & - & - & $\begin{array}{c}3 \\
0,3\end{array}$ & - & - & $\begin{array}{c}2 \\
0,5\end{array}$ & $\begin{array}{c}2 \\
0,1\end{array}$ & - & $\begin{array}{c}2 \\
0,2\end{array}$ & $\begin{array}{c}5 \\
0,4\end{array}$ \\
\hline Trophon geversianus & $\begin{array}{l}\mathrm{N} \\
\%\end{array}$ & $\begin{array}{l}38 \\
0,6 \\
\end{array}$ & $\begin{array}{c}2 \\
0,1\end{array}$ & $\begin{array}{r}10 \\
0,5 \\
\end{array}$ & $\begin{array}{c}5 \\
0,2 \\
\end{array}$ & - & $\begin{array}{c}1 \\
0,1 \\
\end{array}$ & $\begin{array}{c}4 \\
0,5 \\
\end{array}$ & $\begin{array}{c}2 \\
0,7\end{array}$ & $\begin{array}{c}1 \\
0,3 \\
\end{array}$ & $\begin{array}{c}2 \\
0,1\end{array}$ & - & $\begin{array}{c}2 \\
0,2 \\
\end{array}$ & $\begin{array}{c}5 \\
0,4\end{array}$ \\
\hline Acantina monodon & $\begin{array}{l}\mathrm{N} \\
\%\end{array}$ & $\begin{array}{l}1 \\
0\end{array}$ & - & - & $\begin{array}{c}1 \\
0,1\end{array}$ & - & - & - & - & - & - & - & - & - \\
\hline Buccinulum meridionalis & $\begin{array}{l}\mathrm{N} \\
\%\end{array}$ & - & - & $\begin{array}{l}1 \\
0\end{array}$ & - & - & - & - & - & - & - & - & - & - \\
\hline Buccinanops globosum & $\begin{array}{l}\mathrm{N} \\
\% \\
\end{array}$ & - & - & - & $\begin{array}{c}2 \\
0,1 \\
\end{array}$ & - & - & - & - & - & - & - & - & - \\
\hline Kerguelenella lateralis & $\begin{array}{l}\mathrm{N} \\
\%\end{array}$ & $\begin{array}{l}59 \\
0,9\end{array}$ & $\begin{array}{c}31 \\
1\end{array}$ & $\begin{array}{l}30 \\
1,4\end{array}$ & $\begin{array}{c}9 \\
0,3\end{array}$ & $\begin{array}{c}9 \\
1,5\end{array}$ & $\begin{array}{c}4 \\
0,4\end{array}$ & - & $\begin{array}{c}6 \\
0,2\end{array}$ & $\begin{array}{c}2 \\
0,5\end{array}$ & $\begin{array}{c}5 \\
0,1\end{array}$ & $\begin{array}{c}1 \\
0,4\end{array}$ & $\begin{array}{c}2 \\
0,2\end{array}$ & $\begin{array}{c}4 \\
0,3\end{array}$ \\
\hline Siphonaria lessoni & $\begin{array}{l}\mathrm{N} \\
\%\end{array}$ & $\begin{array}{l}22 \\
0,3 \\
\end{array}$ & $\begin{array}{c}5 \\
0,1 \\
\end{array}$ & $\begin{array}{c}9 \\
0,4 \\
\end{array}$ & $\begin{array}{l}12 \\
0,4 \\
\end{array}$ & $\begin{array}{c}7 \\
1,2 \\
\end{array}$ & $\begin{array}{l}16 \\
1,5 \\
\end{array}$ & $\begin{array}{c}2 \\
0,2 \\
\end{array}$ & $\begin{array}{c}4 \\
0,1 \\
\end{array}$ & - & $\begin{array}{c}3 \\
0,1 \\
\end{array}$ & - & - & $\begin{array}{c}1 \\
0,1 \\
\end{array}$ \\
\hline Iothia emarginuloides & $\begin{array}{l}\mathrm{N} \\
\%\end{array}$ & - & - & - & $\begin{array}{c}1 \\
0,1\end{array}$ & - & - & - & - & - & - & - & - & - \\
\hline Fissurella sp. & $\begin{array}{l}\mathrm{N} \\
\%\end{array}$ & $\begin{array}{c}5 \\
0,1 \\
\end{array}$ & $\begin{array}{c}5 \\
0,1\end{array}$ & $\begin{array}{c}13 \\
0,6\end{array}$ & $\begin{array}{l}11 \\
0,4\end{array}$ & - & $\begin{array}{c}4 \\
0,4\end{array}$ & $\begin{array}{c}4 \\
0,5\end{array}$ & $\begin{array}{l}1 \\
0 \\
\end{array}$ & 0 & $\begin{array}{c}3 \\
0,1 \\
\end{array}$ & - & - & $\begin{array}{c}4 \\
0,3 \\
\end{array}$ \\
\hline Eumetula pulla & $\begin{array}{l}\mathrm{N} \\
\% \\
\end{array}$ & $\begin{array}{l}1 \\
0 \\
\end{array}$ & - & - & - & - & - & - & $\begin{array}{l}1 \\
0 \\
\end{array}$ & - & - & - & - & - \\
\hline Epitonium magellanicum & $\begin{array}{l}\mathrm{N} \\
\%\end{array}$ & - & - & - & $\begin{array}{c}1 \\
0,1\end{array}$ & - & - & - & - & - & - & - & - & - \\
\hline Gasteropodo indet. & $\begin{array}{l}\mathrm{N} \\
\%\end{array}$ & $\begin{array}{l}47 \\
0,7\end{array}$ & $\begin{array}{c}3 \\
0,1 \\
\end{array}$ & $\begin{array}{c}18 \\
0,9\end{array}$ & $\begin{array}{l}10 \\
0,4 \\
\end{array}$ & - & $\begin{array}{c}3 \\
0,3\end{array}$ & $\begin{array}{c}2 \\
0,2\end{array}$ & $\begin{array}{c}3 \\
0,1\end{array}$ & $\begin{array}{l}4 \\
1\end{array}$ & - & - & - & - \\
\hline \multicolumn{15}{|c|}{ Cl. Bivalvia } \\
\hline Mytilus edulis & $\begin{array}{l}\mathrm{N} \\
\% \\
\end{array}$ & $\begin{array}{l}2148 \\
32,4 \\
\end{array}$ & $\begin{array}{r}726 \\
20,6 \\
\end{array}$ & $\begin{array}{l}413 \\
19,5 \\
\end{array}$ & $\begin{array}{r}761 \\
28,2 \\
\end{array}$ & $\begin{array}{c}488 \\
81 \\
\end{array}$ & $\begin{array}{l}447 \\
42,8 \\
\end{array}$ & $\begin{array}{r}343 \\
40,7 \\
\end{array}$ & $\begin{array}{l}1420 \\
50,3 \\
\end{array}$ & $\begin{array}{l}60 \\
17 \\
\end{array}$ & $\begin{array}{r}848 \\
25,5 \\
\end{array}$ & $\begin{array}{c}57 \\
27,4 \\
\end{array}$ & $\begin{array}{r}337 \\
\mathbf{4 4 , 6} \\
\end{array}$ & $\begin{array}{r}545 \\
44,6 \\
\end{array}$ \\
\hline Aulacomya atra & $\begin{array}{l}\mathrm{N} \\
\%\end{array}$ & $\begin{array}{c}466 \\
7\end{array}$ & $\begin{array}{l}101 \\
2,9\end{array}$ & $\begin{array}{l}137 \\
6,5\end{array}$ & $\begin{array}{l}873 \\
32,2\end{array}$ & $\begin{array}{l}6 \\
1\end{array}$ & $\begin{array}{l}26 \\
2,5\end{array}$ & $\begin{array}{l}24 \\
2,9\end{array}$ & $\begin{array}{l}320 \\
11,3\end{array}$ & $\begin{array}{l}25 \\
7,1\end{array}$ & $\begin{array}{c}330 \\
10\end{array}$ & $\begin{array}{c}36 \\
15,6\end{array}$ & $\begin{array}{c}30 \\
4\end{array}$ & $\begin{array}{l}39 \\
3,2\end{array}$ \\
\hline Perumytilus purpuratus & $\begin{array}{l}\mathrm{N} \\
\%\end{array}$ & $\begin{array}{c}660 \\
10 \\
\end{array}$ & $\begin{array}{l}114 \\
3,2 \\
\end{array}$ & $\begin{array}{l}556 \\
26,3 \\
\end{array}$ & $\begin{array}{l}389 \\
14,4 \\
\end{array}$ & $\begin{array}{l}50 \\
8,3 \\
\end{array}$ & $\begin{array}{l}299 \\
28,6 \\
\end{array}$ & $\begin{array}{l}60 \\
7,1 \\
\end{array}$ & $\begin{array}{l}300 \\
10,6 \\
\end{array}$ & $\begin{array}{l}25 \\
7,1 \\
\end{array}$ & $\begin{array}{l}314 \\
9,5 \\
\end{array}$ & $\begin{array}{l}15 \\
6,5 \\
\end{array}$ & $\begin{array}{l}42 \\
5,5 \\
\end{array}$ & $\begin{array}{l}92 \\
7,5 \\
\end{array}$ \\
\hline Leukoma antiqua & $\begin{array}{l}\mathrm{N} \\
\%\end{array}$ & - & - & - & - & - & - & $\begin{array}{c}2 \\
0,2\end{array}$ & $\begin{array}{l}1 \\
0\end{array}$ & - & - & - & - & - \\
\hline Tawera elliptica & $\begin{array}{l}\mathrm{N} \\
\%\end{array}$ & $\begin{array}{l}1 \\
0\end{array}$ & $\begin{array}{l}1 \\
0\end{array}$ & $\begin{array}{c}7 \\
0,3 \\
\end{array}$ & $\begin{array}{l}11 \\
0,4\end{array}$ & - & - & - & $\begin{array}{c}6 \\
0,2\end{array}$ & $\begin{array}{l}11 \\
3,1\end{array}$ & $\begin{array}{c}6 \\
0,2\end{array}$ & $\begin{array}{c}2 \\
0,9\end{array}$ & $\begin{array}{c}3 \\
0,4\end{array}$ & $\begin{array}{c}1 \\
0,1\end{array}$ \\
\hline Petricolaria patagónica & $\begin{array}{l}\mathrm{N} \\
\%\end{array}$ & - & - & - & $\begin{array}{c}1 \\
0,1\end{array}$ & - & - & - & - & - & - & - & - & - \\
\hline Darina solenoides & $\begin{array}{l}\mathrm{N} \\
\%\end{array}$ & - & - & - & $\begin{array}{c}2 \\
0,1\end{array}$ & - & $\begin{array}{c}7 \\
0,7 \\
\end{array}$ & $\begin{array}{c}1 \\
0,1\end{array}$ & $\begin{array}{c}1 \\
0,1 \\
\end{array}$ & - & - & - & - & - \\
\hline Hiatela artica & $\begin{array}{l}\mathrm{N} \\
\%\end{array}$ & - & $\begin{array}{l}1 \\
0\end{array}$ & $\begin{array}{l}1 \\
0\end{array}$ & $\begin{array}{c}3 \\
0,1\end{array}$ & - & - & - & - & - & - & - & - & - \\
\hline Gari solida & $\begin{array}{l}\mathrm{N} \\
\%\end{array}$ & - & - & - & - & - & - & $\begin{array}{c}1 \\
0,1 \\
\end{array}$ & - & - & - & - & - & - \\
\hline Ensis macha & $\begin{array}{l}\mathrm{N} \\
\% \\
\end{array}$ & - & - & $\begin{array}{l}1 \\
0 \\
\end{array}$ & $\begin{array}{r}11 \\
0,4 \\
\end{array}$ & $\begin{array}{c}1 \\
0,2 \\
\end{array}$ & $\begin{array}{c}1 \\
0,1 \\
\end{array}$ & $\begin{array}{c}1 \\
0,1 \\
\end{array}$ & - & - & - & $\begin{array}{c}3 \\
1,3 \\
\end{array}$ & - & - \\
\hline F. Veneridae & $\begin{array}{l}\mathrm{N} \\
\%\end{array}$ & - & $\begin{array}{l}1 \\
0\end{array}$ & - & $\begin{array}{c}3 \\
0,1\end{array}$ & - & $\begin{array}{c}1 \\
0,1\end{array}$ & - & - & $\begin{array}{c}1 \\
0,3\end{array}$ & - & - & - & - \\
\hline \multicolumn{15}{|c|}{ Cl. Polyplacophora } \\
\hline Neoloricata & $\begin{array}{l}\mathrm{N} \\
\%\end{array}$ & $\begin{array}{c}4 \\
0,1 \\
\end{array}$ & - & $\begin{array}{c}5 \\
0,2 \\
\end{array}$ & $\begin{array}{c}4 \\
0,2 \\
\end{array}$ & - & $\begin{array}{c}1 \\
0,1 \\
\end{array}$ & $\begin{array}{c}2 \\
0,2\end{array}$ & $\begin{array}{l}1 \\
0\end{array}$ & $\begin{array}{c}1 \\
0,3 \\
\end{array}$ & $\begin{array}{l}1 \\
0 \\
\end{array}$ & - & $\begin{array}{c}1 \\
0,1 \\
\end{array}$ & $\begin{array}{c}1 \\
0,1 \\
\end{array}$ \\
\hline Total & $\mathbf{N}$ & 6630 & 3527 & 2116 & 2698 & 602 & 1045 & 842 & 2823 & 351 & 3323 & 231 & 755 & 1220 \\
\hline Riqueza & $\mathbf{N}$ & 18 & 15 & 16 & 22 & 9 & 16 & 15 & 16 & 13 & 13 & 9 & 10 & 12 \\
\hline
\end{tabular}

TABLA 2

Taxones de moluscos registrados en los concheros (NMI). En negrita se resalta la especie predominante. Referencias: S1: Sondeo 1; S2: Sondeo 2.

Archaeofauna 27 (2018): 7-20 
todos los conjuntos asciende a 26163. La riqueza malacológica total entre los sitios es de 29 (Tabla 2). En cinco de los concheros predomina la especie Nacella magellanica, en cuatro Mytilus edulis y en uno Aulacomya atra (Tabla 2). Estas especies habitan el mesolitoral e infralitoral superior en plataformas de abrasión rocosas (Aguirre et al., 2009).

Las restantes especies de gasterópodos y bivalvos aparecen en bajas frecuencias (Tabla 2). Algunas de las especies de bivalvos aparecen en fondos de sustratos arenosos enterradas en el sedimentos (e.g. Leukoma antiqua, Tawera elliptica, Ensis macha o Eurhomalea exalbida). La frecuencia de restos de poliplacóforos es baja en la totalidad de las muestras analizadas.
Preservación de los restos arqueomalacológicos y procesos tafonómicos

En la Tabla 3 se presenta la frecuencia de restos de las principales especies y las pautas tafonómicas. Altas frecuencias de restos en todos los conjuntos se hallan alterados térmicamente. Este proceso podría estar relacionado con el procesamiento y posterior descarte de los moluscos en las zonas de hogar de los campamentos (Hammond, 2015).

Diversos restos presentan evidencias de abrasión lo que evidencia la permanencia de las conchas en superficie, expuestas a las condiciones medioambientales y al efecto del movimiento de partículas sedimentarias que generan superficies porosas.

\begin{tabular}{|c|c|c|c|c|c|c|c|c|c|c|c|c|c|c|c|c|c|c|c|c|c|}
\hline \multirow{2}{*}{\multicolumn{2}{|c|}{ Variables }} & \multicolumn{4}{|c|}{ UNPA } & \multicolumn{4}{|c|}{ Puerto Jenkins 2} & \multicolumn{4}{|c|}{ Playa del Negro } & \multicolumn{4}{|c|}{ Las Hormigas } & \multicolumn{4}{|c|}{ Sitio 112} \\
\hline & & $\mathrm{Nm}$ & $M e$ & $A a$ & $P p$ & $\mathrm{Nm}$ & $\mathrm{Me}$ & $A a$ & $P p$ & $\mathrm{Nm}$ & $M e$ & $A a$ & $P p$ & $\mathrm{Nm}$ & $M e$ & $A a$ & $P p$ & $\mathrm{Nm}$ & $M e$ & $A a$ & $P p$ \\
\hline \multirow{4}{*}{ 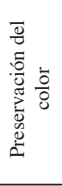 } & Color original & 1 & - & - & - & - & - & - & - & - & - & - & - & - & 1 & 45 & 2 & - & - & - & - \\
\hline & $\begin{array}{l}\text { Preservación } \\
\text { parcial }\end{array}$ & 1172 & 930 & 45 & 498 & - & 205 & 55 & 33 & - & 43 & 14 & 1 & 28 & 480 & 54 & 459 & 5 & 28 & - & - \\
\hline & Pérdida total & 280 & 92 & 7 & 242 & 1963 & 242 & 7 & 112 & 398 & 38 & 25 & 593 & 379 & 17 & 102 & 66 & 23 & 754 & 6 & 87 \\
\hline & $\begin{array}{l}\text { Calcinación } \\
\text { solar }\end{array}$ & 3 & - & - & 3 & 2 & - & - & - & - & - & - & 2 & 14 & - & 3 & - & 3 & - & - & - \\
\hline \multicolumn{2}{|c|}{$\begin{array}{l}\text { Preservación del } \\
\text { periostraco }\end{array}$} & - & 6 & - & - & - & 1 & - & - & - & - & 1 & - & - & 384 & 462 & 342 & - & - & - & - \\
\hline \multicolumn{2}{|c|}{ Signos de corrosión } & 187 & 41 & - & 168 & 1240 & 160 & 5 & 75 & 308 & 33 & 12 & 382 & 348 & 140 & 122 & 47 & 23 & 358 & - & 21 \\
\hline \multicolumn{2}{|c|}{ Signos de abrasión } & 240 & 82 & 2 & 66 & 433 & 55 & 4 & 31 & 19 & 24 & 5 & 14 & 3 & 3 & 1 & 1 & - & - & - & 4 \\
\hline \multicolumn{2}{|c|}{ Incrustaciones } & 9 & - & 2 & - & 3 & 2 & - & 1 & 5 & - & - & - & 4 & - & 14 & - & - & 1 & - & 1 \\
\hline \multicolumn{2}{|c|}{ Bioerosión } & - & 1 & 2 & 9 & 8 & - & - & - & - & 1 & - & 10 & - & 8 & - & - & - & - & - & 1 \\
\hline \multicolumn{2}{|c|}{ Alteración térmica } & 1358 & 1022 & 52 & 743 & 1963 & 447 & 62 & 145 & 398 & 81 & 38 & 596 & 335 & 322 & 233 & 156 & 31 & 782 & 6 & 87 \\
\hline \multicolumn{2}{|c|}{$\begin{array}{l}\text { Rotura/impacto en } \\
\text { Nacella sp. }\end{array}$} & 306 & - & - & - & 461 & - & - & - & 75 & - & - & - & & - & - & - & 3 & - & - & - \\
\hline \multicolumn{2}{|l|}{ Total } & \multicolumn{4}{|c|}{3273} & \multicolumn{4}{|c|}{2619} & \multicolumn{4}{|c|}{1114} & \multicolumn{4}{|c|}{2130} & \multicolumn{4}{|c|}{906} \\
\hline \multirow{2}{*}{\multicolumn{2}{|c|}{ Variables }} & \multicolumn{4}{|c|}{ Sitio 160} & \multicolumn{4}{|c|}{ Médano 1} & \multicolumn{4}{|c|}{ Punta Buque 1} & & uesto & alize & & & uesto & aliza & \\
\hline & & $\mathrm{Nm}$ & $M e$ & $A a$ & $P p$ & $\mathrm{Nm}$ & $M e$ & $A a$ & $P p$ & $\mathrm{Nm}$ & $M e$ & $A a$ & $P p$ & $\mathrm{Nm}$ & $M e$ & $A a$ & $P p$ & $\mathrm{Nm}$ & $M e$ & $A a$ & $P p$ \\
\hline & Color original & 3 & 6 & - & 2 & - & - & - & - & - & - & - & - & - & - & - & - & - & - & - & - \\
\hline 흥 & $\begin{array}{l}\text { Preservación } \\
\text { parcial }\end{array}$ & 31 & 980 & 11 & 348 & 7 & 241 & 8 & 22 & 1443 & 1225 & 379 & 567 & 10 & 13 & 2 & 3 & 415 & 741 & 55 & 138 \\
\hline 28 & Pérdida total & 47 & 64 & 1 & 234 & 192 & 1229 & 47 & 542 & 210 & 64 & 12 & 60 & 31 & 2 & 3 & 6 & 150 & 37 & 6 & 29 \\
\hline & $\begin{array}{l}\text { Calcinación } \\
\text { solar }\end{array}$ & 2 & - & - & - & 10 & 1 & - & - & 21 & - & - & - & 20 & - & 4 & 1 & 41 & - & - & 2 \\
\hline $\begin{array}{l}\text { Preserv } \\
\text { periost }\end{array}$ & $\begin{array}{l}\text { ación del } \\
\text { aco }\end{array}$ & - & 330 & 2 & 179 & - & - & - & - & - & 453 & 30 & 183 & - & - & - & - & - & 40 & 7 & - \\
\hline Signos & de corrosión & 25 & 89 & - & 51 & 167 & 724 & 10 & 286 & 90 & 4 & 1 & 49 & - & - & - & - & 26 & - & - & 20 \\
\hline Signos & de abrasión & 2 & 241 & 1 & - & 1 & - & - & 8 & 271 & 85 & 11 & 50 & 56 & 13 & 8 & 2 & 172 & 80 & 3 & 32 \\
\hline Incrust & aciones & - & 7 & - & 2 & - & - & - & - & 8 & - & 10 & 1 & - & - & - & - & 1 & - & - & - \\
\hline Bioero & ión & 1 & 1 & - & - & - & - & - & - & 3 & - & 7 & 7 & - & - & - & - & - & - & - & 3 \\
\hline Alterac & ión térmica & 37 & 542 & 10 & 416 & 194 & 1471 & 55 & 378 & 1636 & 1289 & 391 & 627 & 51 & 9 & 5 & 10 & 558 & 682 & 56 & 152 \\
\hline $\begin{array}{l}\text { Rotura/ } \\
\text { Nacellc }\end{array}$ & $\begin{array}{l}\text { impacto en } \\
\text { sp. }\end{array}$ & 10 & - & - & - & 56 & - & - & - & 24 & - & - & - & & - & - & - & 116 & - & - & - \\
\hline Total & & & 17 & & & & 22 & & & & 39 & & & & & & & & & & \\
\hline
\end{tabular}

TABLA 3

Preservación de los materiales arqueomalacológicos (frecuencia). Referencias: Nm: Nacella magellanica; Me: Mytilus edulis; Aa: Aulacomya atra; Pp: Perumytilus purpuratus. 
En la mayoría de los conjuntos las conchas han perdido de forma parcial o total el color original. Escasos restos presentan evidencias de calcinación solar.

En los sitios Las Hormigas, Punta Buque 1 y Sitio 160 se registraron altas frecuencias de valvas de mitílidos con preservación del periostraco (Tabla $3)$. La preservación de esta membrana de composición proteica se asocia, en estos casos, a contextos en los que la matriz sedimentaria presenta valores de $\mathrm{pH}$ medianamente alcalinos y está compuesta por sedimentos eólicos finos de tamaño arena, en los cuales es factible que se produzca una rápida cobertura de los restos arqueológicos debido principalmente a la dinámica eólica.

Solo en el sitio UNPA se detectaron 41 conchas de Nacella sp. con deformación. Este proceso habría sido consecuencia de la alta compactación de la matriz sedimentaria y la presencia de humedad en el sustrato (en matrices secas la alternativa suele ser la fracturación).

Las modificaciones producidas por organismos como briozoos, esponjas o moluscos perforantes (natícidos o murícidos), y la presencia de fauna incrustante (por ejemplo, Balanus sp.) en bajas frecuencia en todos los conjuntos (Tabla 3).

Entre un $12 \%$ y un $37 \%$ de las conchas de $\mathrm{Na}$ cella magellanica presentan evidencias fracturas en su periferia (con morfologías redondeadas u ovaladas y bordes irregulares) y/o signos impacto (parte de la concha con un hundimiento circular $\mathrm{u}$ ovalado; Tabla 3). Estas modificaciones se postulan relacionadas con acciones antrópicas destinadas a separar al animal de su substrato (Hammond \& Zilio, 2016).

\section{Conservación de los restos arqueomalacológicos y} estructura de los sitios

La fragmentación de los materiales arqueomalacológicos se ha identificado en la totalidad de los conjuntos. La variabilidad de esta fragmentación entre especies es producto de las diferencias morfológicas y composición de las conchas (caso de la forma, el tamaño, la escultura, el grosor y la microestructura), además de los procesos tafonómicos que afectaron a cada conjunto. En la totalidad de las muestras la conservación de conchas de Nacella magellanica es mejor que la de las valvas de Mytilus edulis y Aulacomya atra (Tabla 4). Este hecho podría deberse a que las primeras poseen una estructura calcárea más gruesa, con morfología compacta y posiblemente más resistente al deterioro y a la fragmentación. Las valvas de Mytilus edulis y Aulacomya atra son más alargadas, delgadas y frágiles, lo que influye en su susceptibilidad a la fragmentación y conservación. Los porcentajes de valvas completas de Perumytilus purpuratus son variables entre muestras.

Los porcentajes más altos de fragmentación se registraron en los sitios UNPA, 112, Médano 1 y Puesto Baliza 1 y 2 (Tabla 4). En el primero las conchas se encontraban muy compactadas y fracturadas, principalmente como consecuencia de la dinámica de ocupación humana del sitio y debido a la presencia de humedad en el sustrato areno-gravoso. Los restos habrían sido objeto de pisoteo y por su parte, la compactación de la matriz del depósito también afectó la conservación de los materiales. En el Sitio 112 la fragmentación está influenciada por la fragilidad de las conchas debido a la exposición a altas temperaturas. En el sitio Médano 1 los restos se hallaban muy fragmentados y compactados en una matriz sedimentaria con alto contenido de humedad.

Los sitios conformados por una alta densidad de moluscos presentan en general fábricas de tipo bioclasto-sostenidas, en cambio los concheros con menor densidad, fábricas matriz-sostenidas (Tabla 1). Los primeros muestran mejor integridad (Binford, 1981) debido a que las conchas, en contacto, conforman una estructura compacta que ofrece mayor resistencia a los procesos de erosión y eliminación de los materiales. Las fábricas matriz-sostenidas poseen mayor susceptibilidad a los agentes post-deposicionales, como la erosión eólica y la bioturbación. En estos contextos cabe esperar menor integridad y baja resolución (Stein, 1987). La configuración como montículo de los sitios emplazados en dunas o mantos eólicos, lo genera el proceso de deflación que produce la caída y desplazamiento de los materiales arqueológicos por los taludes. Los concheros emplazados en cordones litorales o planicies de mareas se configuran como acumulaciones extendidas en superficie.

\section{Biometría}

La Tabla 5 refiere a la talla (longitud o diámetro máximo) de las conchas de las especies dominantes. 


\begin{tabular}{|c|c|c|c|c|c|}
\hline Concheros & Taxones/Conservación & ICOM-VCOM & IFRA-VFRA & FAPI-FCHC & Total \\
\hline \multirow[t]{4}{*}{ UNPA } & Nacella magellanica & $1128(42 \%)$ & $464(17,3 \%)$ & $1091(40,7 \%)$ & 2683 \\
\hline & Mytius edulis & $59(1,4 \%)$ & $1037(26 \%)$ & $2906(72,6 \%)$ & 4002 \\
\hline & Aulacomya atra & $1(0,1 \%)$ & $74(10,6 \%)$ & $625(89,3 \%)$ & 700 \\
\hline & Perumytilus purpuratus & $178(15 \%)$ & $686(57,5 \%)$ & $328(27,5 \%)$ & 1192 \\
\hline \multirow[t]{4}{*}{ Puerto Jenkins 2} & Nacella magellanica & $1683(69 \%)$ & $484(19,8 \%)$ & $273(11,2 \%)$ & 2440 \\
\hline & Mytius edulis & $162(11,7 \%)$ & $863(62 \%)$ & $365(26,3 \%)$ & 1390 \\
\hline & Aulacomya atra & $5(3 \%)$ & $80(48,8 \%)$ & $79(48,2 \%)$ & 164 \\
\hline & Perumytilus purpuratus & $98(47,3 \%)$ & $107(51,7 \%)$ & $2(1 \%)$ & 207 \\
\hline \multirow[t]{4}{*}{ Playa del Negro } & Nacella magellanica & $368(45,4 \%)$ & $127(15,6 \%)$ & $316(39 \%)$ & 811 \\
\hline & Mytius edulis & $30(4,2 \%)$ & $585(81 \%)$ & $107(14,8 \%)$ & 722 \\
\hline & Aulacomya atra & $14(6 \%)$ & $41(17,5 \%)$ & $179(76,5 \%)$ & 234 \\
\hline & Perumytilus purpuratus & $326(32,7 \%)$ & $615(61,8 \%)$ & $55(5,5 \%)$ & 996 \\
\hline \multirow[t]{4}{*}{ Las Hormigas } & Nacella magellanica & $401(78,8 \%)$ & $60(11,8 \%)$ & $48(9,4 \%)$ & 509 \\
\hline & Mytius edulis & $337(23 \%)$ & $685(46,9 \%)$ & $440(30,1 \%)$ & 1462 \\
\hline & Aulacomya atra & $505(30,5 \%)$ & $556(33,5 \%)$ & $597(36 \%)$ & 1658 \\
\hline & Perumytilus purpuratus & $509(71,8 \%)$ & $200(28,2 \%)$ & $0(0 \%)$ & 709 \\
\hline \multirow[t]{4}{*}{ Sitio 112} & Nacella magellanica & $25(71,4 \%)$ & $6(17,2 \%)$ & $4(11,4 \%)$ & 35 \\
\hline & Mytius edulis & $92(9,8 \%)$ & $672(71,4 \%)$ & $177(18,8 \%)$ & 941 \\
\hline & Aulacomya atra & $1(10 \%)$ & $5(50 \%)$ & $4(40 \%)$ & 10 \\
\hline & Perumytilus purpuratus & $60(73,2 \%)$ & $22(26,8 \%)$ & $0(0 \%)$ & 82 \\
\hline \multirow[t]{4}{*}{ Sitio 160} & Nacella magellanica & $111(86,7 \%)$ & $13(10,2 \%)$ & $4(3,1 \%)$ & 128 \\
\hline & Mytius edulis & $521(34,8 \%)$ & $733(49 \%)$ & $243(16,2 \%)$ & 1497 \\
\hline & Aulacomya atra & $7(9,7 \%)$ & $11(15,3 \%)$ & $54(75 \%)$ & 72 \\
\hline & Perumytilus purpuratus & $438(65,4 \%)$ & $223(33,3 \%)$ & $9(1,3 \%)$ & 670 \\
\hline \multirow[t]{4}{*}{ Médano 1} & Nacella magellanica & $176(76,9 \%)$ & $33(14,4 \%)$ & $20(8,7 \%)$ & 229 \\
\hline & Mytius edulis & $55(2 \%)$ & $1416(52,4 \%)$ & $1233(45,6 \%)$ & 2704 \\
\hline & Aulacomya atra & $5(0,8 \%)$ & $50(8,4 \%)$ & $542(90,8 \%)$ & 597 \\
\hline & Perumytilus purpuratus & $89(15,8 \%)$ & $475(84,2 \%)$ & $0(0 \%)$ & 564 \\
\hline \multirow[t]{4}{*}{ Punta Buque 1} & Nacella magellanica & $1379(76 \%)$ & $295(16,3 \%)$ & $139(7,7 \%)$ & 1813 \\
\hline & Mytius edulis & $492(28,8 \%)$ & $797(46,6 \%)$ & $420(24,6 \%)$ & 1709 \\
\hline & Aulacomya atra & $120(18 \%)$ & $271(40,7 \%)$ & $275(41,3 \%)$ & 666 \\
\hline & Perumytilus purpuratus & $264(42,1 \%)$ & $363(57,9 \%)$ & $0(0 \%)$ & 627 \\
\hline \multirow[t]{4}{*}{ Puesto Baliza 1} & Nacella magellanica & $49(47,1 \%)$ & $12(11,5 \%)$ & $43(41,3 \%)$ & 104 \\
\hline & Mytius edulis & $3(3,1 \%)$ & $12(12,4 \%)$ & $82(84,5 \%)$ & 97 \\
\hline & Aulacomya atra & $1(1,9 \%)$ & $8(15,4 \%)$ & $43(82,7 \%)$ & 52 \\
\hline & Perumytilus purpuratus & $5(21,7 \%)$ & $5(21,7 \%)$ & $13(56,5 \%)$ & 23 \\
\hline \multirow[t]{4}{*}{ Puesto Baliza 2} & Nacella magellanica & $521(68,1 \%)$ & $82(10,7 \%)$ & $162(21,2 \%)$ & 765 \\
\hline & Mytius edulis & $137(8,3 \%)$ & $647(39,2 \%)$ & $866(52,5 \%)$ & 1650 \\
\hline & Aulacomya atra & $17(14 \%)$ & $41(33,9 \%)$ & $63(52,1 \%)$ & 121 \\
\hline & Perumytilus purpuratus & $88(43,3 \%)$ & $81(40 \%)$ & $34(16,7 \%)$ & 203 \\
\hline
\end{tabular}

TABLA 4

Conservación de las estructuras calcáreas de las cuatro especies más representadas en los concheros.

En la Figura 2 se presenta la distribución de las medias de las longitudes, anchura y altura (en $\mathrm{mm}$ ) para las cuatro especies dominantes junto con fechados radiocarbónicos. En la figura se incluye el coeficiente de correlación lineal $\left(\mathrm{R}^{2}\right)$ para cada una de las medias de las medidas biométricas.

En todos los casos los coeficientes de correlación lineal obtenidos presentan valores cercanos a
0 (estadísticamente existen correlaciones positivas débiles). En el caso de Mytilus edulis la correlación es muy débil. Sin embargo, en los gráficos se aprecia que la regresión lineal marca una tendencia que indica la disminución del tamaño medio de los moluscos desde hace $c a .3000$ años AP hasta $c a$. 300 años AP. 


\begin{tabular}{|c|c|c|c|c|}
\hline \multicolumn{2}{|l|}{ Sitio } & Nacella magellanica & Mytilus edulis & Aulacomya atra \\
\hline \multicolumn{2}{|l|}{ UNPA } & $39,10 \pm 5,7(\mathrm{n}=1082)$ & $47,9 \pm 10,2(\mathrm{n}=58)$ & - \\
\hline \multicolumn{2}{|l|}{ Puerto Jenkins 2} & $42,93 \pm 4,23(n=1683)$ & $51,45 \pm 10,92(\mathrm{n}=162)$ & $49,04 \pm 20,07(\mathrm{n}=5)$ \\
\hline \multicolumn{2}{|l|}{ Playa del Negro } & $34,90 \pm 6,22(n=368)$ & $47,89 \pm 8,81(\mathrm{n}=30)$ & $73,47 \pm 15,16(n=14)$ \\
\hline \multicolumn{2}{|l|}{ Las Hormigas } & $35,70 \pm 7,78(\mathrm{n}=401)$ & $41,35 \pm 19,95(n=337)$ & $47,07 \pm 28,5(\mathrm{n}=505)$ \\
\hline \multicolumn{2}{|l|}{ Sitio 112} & $42,47 \pm 7,26(\mathrm{n}=25)$ & $51,52 \pm 6,19(\mathrm{n}=92)$ & - \\
\hline \multirow{2}{*}{ Sitio 160} & S1 & $32,65 \pm 11,42(\mathrm{n}=59)$ & $51,64 \pm 8,38(\mathrm{n}=252)$ & $70,16 \pm 12,81 \quad(n=6)$ \\
\hline & $\mathrm{S} 2$ & $40,97 \pm 6,76(n=52)$ & $56,02 \pm 10,69(\mathrm{n}=275)$ & $71,65 \pm 9,46(n=2)$ \\
\hline \multicolumn{2}{|l|}{ Médano 1} & $38,62 \pm 5,20(n=176)$ & $48,36 \pm 8,81(\mathrm{n}=55)$ & $63,14 \pm 20,30(n=5)$ \\
\hline \multirow{2}{*}{ Punta Buque 1} & S1 & $40,82 \pm 4,23(n=137)$ & $53,12 \pm 14,72(\mathrm{n}=20)$ & - \\
\hline & S2 & $37,93 \pm 4,29(\mathrm{n}=1242)$ & $47,29 \pm 8,77(\mathrm{n}=472)$ & $70,18 \pm 14,87(n=119)$ \\
\hline \multicolumn{2}{|l|}{ Puesto Baliza 1} & $39,67 \pm 4,61(n=49)$ & $51,27 \pm 9,67(\mathrm{n}=3)$ & - \\
\hline \multirow{2}{*}{ Puesto Baliza 2} & S1 & $38,31 \pm 5,01(n=207)$ & $48,31 \pm 10,43(n=23)$ & $78,90 \pm 17,33(n=6)$ \\
\hline & S2 & $37,92 \pm 5,02(\mathrm{n}=314)$ & $49 \pm 10,28(n=114)$ & $66,03 \pm 6,43(n=11)$ \\
\hline
\end{tabular}

TABLA 5

Media y desvío estándar de las medidas del largo de tres especies que predominan en los conjuntos arqueomalacológicos.
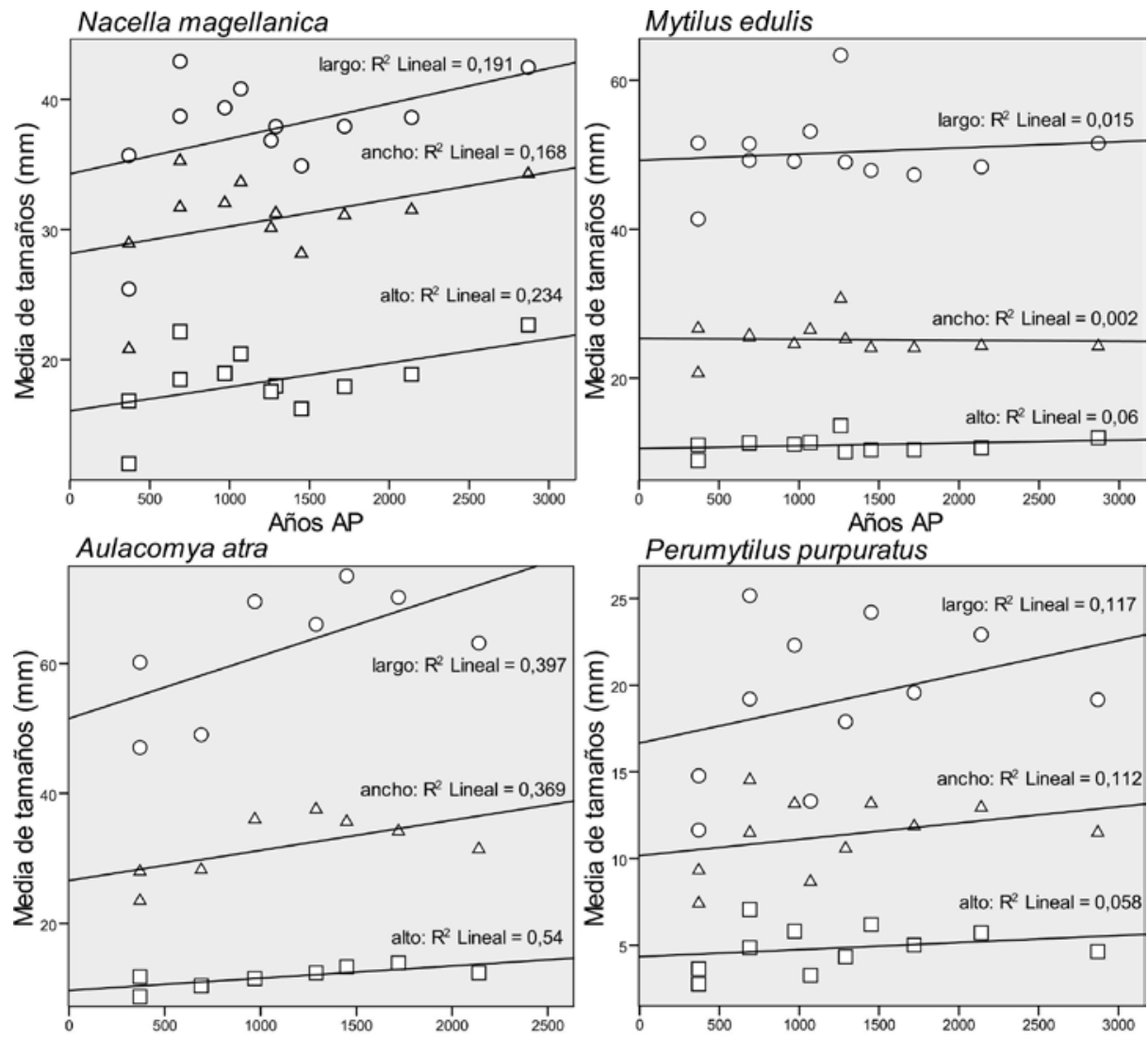

Perumytilus purpuratus

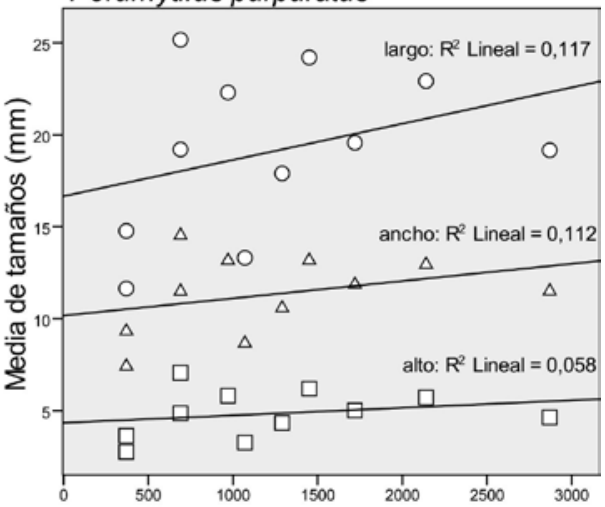

Años AP

FIGURA 2

Coeficiente de correlación lineal tomando en cuenta la media de las medidas biométricas (en mm) de las cuatro especies de moluscos más representadas en los concheros y los fechados radiocarbónicos.

Archaeofauna 27 (2018): 7-20 


\section{DISCUSIÓN}

La arqueomalacofauna: especies con valor alimentario y "acompañantes"

Tres son las especies con mayor valor alimentario que habrían sido recolectadas en los intermareales: Nacella magellanica, Aulacomya atra y Mytilus edulis (Tabla 2). Este hecho coincide con lo identificado para otros concheros del área (Zubimendi \& Hammond, 2009; Zubimendi, 2012; Hammond, 2015, entre otros). Estas tres especies son las más abundantes, alcanzando concentraciones muy altas en zonas próximas al litoral; son por tanto accesibles en el intermareal, y poseen un alto contenido cárnico. También podrían haber preferidas por sus características organolépticas y debido a sus bajas fluctuaciones a lo largo del año (e.d. por su estabilidad).

Otras especies pueden ser caracterizadas como "acompañantes". Estas presentan tamaños pequeños, normalmente por debajo de $30 \mathrm{~mm}$, y se hallan adheridas o son epibiontes de las especies explotadas por los grupos humanos como alimento, por lo que su aparición en las muestras no sería intencional (Orquera \& Piana, 1999, 2000). La presencia de este tipo de moluscos podría evidenciar que en algunos casos las especies principales no se recolectarían individualmente. Tal sería el caso de los racimos de mitílidos, en cuyo biso habitan especies más pequeñas (Orquera \& Piana, 1999). Las especies que pueden ser consideradas como "acompañantes" son: Perumytilus purpuratus, Crepipatella dilatata, Trochita pileus, Pareuthia plumbea, Iothia copingeri, Siphonaria lessoni y Kerguelenella lateralis.

Diversas especies de moluscos caso de ciertos murícidos (por ejemplo, Trophon geversianus o Buccinanops globulosus) y volútidos, son depredadores en los bancos de mejillones que pueden ser considerados también como fauna acompañante (Lasta et al., 1998). El análisis de estas faunas aporta información indirecta sobre las técnicas de recolección, así como sobre las condiciones ecológicas de los sectores donde fueron recolectados los moluscos.

\section{Zonas de recolección}

Las especies malacológicas en los conjuntos prosperan en los intermareales costeros del área
CNSC. A lo largo del litoral se habrían por tanto explotado especies en los intermareales locales, fundamentalmente aquellas de sustratos rocosos. Según Yesner (1980), los estudios etnográficos demuestran que los pueblos costeros raramente viajan más que cortas distancias para recolectar mariscos. Esto se ve reflejado, en que en los concheros arqueológicos las frecuencias de especies varían en relación con las disponibilidades en las plataformas de abrasión cercanas. Esto ha sido constatado en el área de estudio.

Las zonas de recolección habrían estado situadas en sectores de la costa abierta, en los cuales durante las mareas bajas diversas especies quedan expuestas en los sectores superiores y medio del intermareal. Otra de las zonas de recolección se situaría en la cuenca inferior del estuario de la ría Deseado, donde destaca la presencia del mejillinar y los bancos de Aulacomya atra (Zaixso \& Boraso de Zaixso, 2013).

En relación con la zonación vertical, la explotación habría estado centrada en el mesolitoral e infralitoral superior. La dominancia de una u otra especie en cada conchero, respondería por tanto a la disponibilidad y no a factores temporales vinculados con cambios ambientales que hayan repercutido en la ecología de las especies (Aguirre et al., 2009).

\section{Formas de explotación}

Para discutir las formas de explotación se analizaron los cambios en la talla de las principales especies, a partir del estudio de la biometría (Tabla 5). Se observó que en los conjuntos donde predomina Nacella magellanica las desviaciones estándar de las medidas de los mitílidos (Aulacomya atra o Mytilus edulis) son amplias, por lo cual se presume que la recolección podría haber estado orientada a la selección de lapas por tamaño y se habrían recolectado los mitílidos sin selección de talla. Este hecho se postula en Puerto Jenkins 2, Playa del Negro, Puesto Baliza 1, Punta Buque 1 $\mathrm{y}$ en UNPA.

En los concheros donde predominan mitílidos, se aprecia variabilidad en cuanto al tamaño de las especies. En el caso del sitio Las Hormigas, el Sitio 160 y Médano 1, las desviaciones estándar de las valvas de Mytilus edulis y Aulacomya atra son 
relativamente altas, por lo cual la dispersión de los tamaños es amplia. En consecuencia, no se habría producido una selección de tamaño y la recolección se habría llevado a cabo a partir de la obtención en "racimo", junto con fauna "acompañante", introducida accidentalmente al sitio. En los sitios 160 y Médano 1, otra de las características que apoya la hipótesis de la recolección en racimos y la ausencia de una selección de individuos, es la cantidad de conchas de Crepipatella dilatata (Tabla 2), especie considerada como "acompañante" que además presenta tamaños pequeños, inferiores a los $20 \mathrm{~mm}$, con escasa cantidad de carne (Hammond, 2015). Las desviaciones estándar de los tamaños de las valvas de Mytilus edulis en el Sitio 112, apunta a una posible selección de individuos donde los ejemplares presentan un tamaño medio de $50 \mathrm{~mm}$ de longitud. En Puesto Baliza 2, Mytilus edulis presenta tamaños medios de entre 40 y 50 mm de longitud, en tanto que las valvas de Aulacomya atra poseen promedios de entre 60 y $80 \mathrm{~mm}$ de longitud. Por tal razón postulamos que en estos dos últimos sitios los mitílidos podrían haber sido recolectados individualmente en función de su tamaño.

\section{Procesos tafonómicos}

Los grupos humanos fueron los agentes fundamentales involucrados en la formación de los concheros por cuanto tanto el transporte como la acumulación de los restos malacológicos evidencian actividad antrópica. La composición taxonómica de los conjuntos, la densidad de restos y modificaciones tales como la alteración térmica, los impactos y muchas fracturas serían también consecuencia de acciones humanas. Indirectamente, los signos de corrosión pueden relacionarse con el aporte antrópico de materia orgánica a los sitios, y las condiciones de fragmentación de los materiales que forman el depósito pueden variar según la intensidad de ocupación, el pisoteo en el área ocupada, la implementación de acciones de limpieza o el mantenimiento del espacio, entre otras.

Los procesos tafonómicos con mayor relevancia en los conjuntos analizados fueron la alteración térmica, la fragmentación y la pérdida parcial/total del color original de las estructuras calcáreas.

En la mayoría de los sitios, las conchas se hallan alteradas térmicamente como consecuencia de la cocción o apertura de las valvas en el caso de los mitílidos. Este proceso también puede reflejar el descarte de valvas, posterior al consumo de la carne, en hogares (Hammond, 2015). Se trata, de hipótesis pendientes de verificación con estudios experimentales.

La frecuencia de valvas con evidencias de abrasión es un indicador de que los restos permanecieron expuestos en superficie a las condiciones medioambientales durante algún tiempo. Este proceso puede afectar la integridad de los depósitos y producir el deterioro de los restos.

Diversos restos poseen evidencias de corrosión, la cual puede estar relacionada con las condiciones del ambiente en que habitaron los moluscos o del depósito en el que quedaron enterrados (influenciado por las condiciones de humedad, fluctuaciones climáticas y abundancia de vegetación en el sustrato; Aguirre et al., 2011).

La pérdida del color original de las estructuras calcáreas se relacionaría principalmente con la acción de procesos tales como la abrasión, la corrosión y la alteración térmica.

En tres de los conjuntos estudiados se registraron altas frecuencias de valvas con restos del periostraco. En estos casos la preservación se asociaba a contextos con matrices sedimentarias arenosas y ausencia de humedad. En contextos estratigráficos la preservación de esta membrana proteica está también determinada por las condiciones de la matriz sedimentaria tales como el contenido orgánico, el pH, la temperatura y aireación, entre otros (Hammond, 2013).

A partir de los análisis y de estudios experimentales se infirió que las evidencias de roturas y/o signos de impacto en las conchas de Nacella magellanica serían consecuencia de golpes producidos intencionalmente, mediante el uso de instrumentos (Hammond \& Zilio, 2016).

\section{Biometría y gestión de los recursos malacológicos}

Las diferencias de tamaño de las conchas pueden deberse a causas naturales tales como la productividad marina, la temperatura del agua, la velocidad de las corrientes; también a causas ecológicas en el entorno así como a la explotación más o menos intensiva de un taxón, ya que la recolección focalizada generaría una disminución en el 
tamaño (Mannino \& Thomas, 2002; Erlandson \& Rick, 2008; Thakar, 2011).

La tenue reducción en el tamaño de las conchas de las principales especies, podría indicar una explotación mantenida del recurso así como un proceso de intensificación.

El concepto de intensificación en su sentido productivo refiere la capacidad de las poblaciones humanas para obtener más alimentos en una determinada unidad de tiempo o espacial. Este proceso implica un aumento en la producción y eficiencia en la obtención de ciertos recursos e implica estrategias tales como la especialización o la diversificación (Zangrando, 2009). Cabe aclarar que en este caso se postula un proceso de intensificación en el uso del recurso y no una sobreexplotación del mismo. Esta sería la que habría generado una leve disminución en el tamaño medio de los moluscos que, en modo alguno, duplicó su desaparición.

Otro rasgo de las muestras que avala la hipótesis de un impacto antrópico es que las especies que se analizan son plásticas o euritópicas desde el punto de vista ecológico (esto es, tolerantes a variaciones de temperatura, salinidad y a una amplia gama de condiciones ambientales) y presentan un amplio rango de distribución dentro de la Provincia Malacológica Magallánica, por lo que, cambios menores de la temperatura durante el Holoceno tardío en estas latitudes probablemente no hayan afectado a su tamaño, siendo las comunidades bentónicas de estas especies más o menos estables (Gordillo, com. pers.). En este sentido, postulamos que la estructura poblacional de los moluscos en las plataformas de abrasión se habría mantenido estable a través del tiempo.

El proceso de intensificación o la explotación mantenida habría estado relacionado con la reducción de los rangos de movilidad de las poblaciones durante el Holoceno tardío final y con un proceso de reocupación de las localidades arqueológicas ubicadas al sur de la ría Deseado. Estas localidades habrían funcionado como sectores nucleares donde se habrían concentrado ciertos recursos importantes para los grupos humanos, como el agua dulce y los recursos marinos -principalmente aves, pinnípedos y moluscos- (Castro et al., 2003; Zilio, 2015; Zubimendi et al., 2015). La intensificación en el sector costero se habría relacionado además con las condiciones de sequía regional detectadas desde hace $c a .1500$ años AP (Morales et al., 2009), lo que habría provocado que las poblaciones se concentrasen en sectores nucleares estables con disponibilidad de recursos seguros. El proceso de intensificación habría implicado una estrategia de diversificación en el uso de los recursos disponibles, lo que aseguraría un aprovisionamiento continuo y abundante, sin riesgo de sobreexplotación y agotamiento de ningún recurso (Zilio, 2015).

Para el Holoceno tardío el proceso de intensificación en el área CNSC se halla documentado por otras evidencias arqueológicas, como los estudios de vertebrados recuperados en concheros que muestran una amplia riqueza de especies y un meticuloso procesado de las carcasas (Hammond, 2015); también por la existencia de instrumental específico para la caza de pinnípedos, como arpones y rompecráneos, y artefactos para la recolección de moluscos (Moreno, 2008; Beretta et al., 2013; Hammond \& Zilio, 2016); las determinaciones de isótopos estables sobre restos humanos por su parte indican, en un alto porcentaje de los individuos, dietas mixtas con ingesta de recursos marinos y terrestres en proporciones relativamente parejas, además de algunos individuos con dietas predominantemente marinas (Moreno et al., 2011; Zilio et al., 2014; Zilio, 2015); Por último, la recurrencia ocupacional en localidades arqueológicas al sur de la ría Deseado evidenciada por la alta densidad de sitios arqueológicos y la presencia de concentraciones de enterramientos humanos lo que denotarío si no sedentarismo, cuando menos un cierto grado de territorialidad de los grupos humanos (Castro et al., 2003; Zubimendi et al., 2015; Hammond, 2015; Zilio, 2015).

\section{CONCLUSIONES}

Los recursos malacológicos cumplieron un rol significativo en la dieta de las poblaciones que ocuparon el área CNSC. Los moluscos representan recursos seguros, estables y predecibles, que constituirían un complemento alimentario de los pinnípedos (Hammond, 2015). La tenue reducción de la talla de las principales especies, evidenciaría que durante el Holoceno tardío se habría producido un proceso de explotación mantenida y una intensificación del marisqueo, procesos que impactaron en las comunidades malacológicas de las plataformas de abrasión.

A partir de los análisis macroscópicos y de los estudios isotópicos (Moreno et al., 2011; Zilio et al., 2014; Zilio, 2015), es posible plantear que durante el Holoceno tardío el sector de litoral atlánti- 
co bajo estudio habría sido un espacio productivo y seguro para las poblaciones humanas debido a su disponibilidad de diversos tipos de recursos (alimenticios, hídricos, abrigos, etc.).

\section{AGRADECIMIENTOS}

A la Dra. A. Castro y al Dr. L. Zilio por la lectura y las sugerencias realizadas al manuscrito. A los editores y revisores de la revista quienes mediante sus comentarios y sugerencias permitieron mejorar el artículo. Al Consejo Nacional de Investigaciones Científicas y Técnicas (Beca Doctoral y Postdoctoral de la autora) y a la Universidad Nacional de La Plata por el soporte financiero (Proyectos N/594739 dirigidos por A. Castro).

\section{REFERENCIAS}

Aguirre, M.L. 2003: Late Pleistocene and Holocene palaeoenvironments in Golfo San Jorge, Patagonia: molluscan evidence. Marine Geology 194(1): 3-30.

Aguirre, M.L. \& Farinati, E.A. 2000: Moluscos del Cuaternario marino de la Argentina. Boletín de la Academia Nacional de Ciencias 64: 235-333.

Aguirre, M.L.; Richiano, S.M.; Álvarez, F. \& Eastoe, C. 2009: Malacofauna Cuaternaria del litoral norte de Santa Cruz (Patagonia, Argentina). Geobios 42(4): 411-434.

Álvarez Fernández, E. 2009: La explotación de los moluscos marinos en la Cornisa Cantábrica durante el Gravetiense: primeros datos de los niveles E y F de La Garma A (Omoño, Cantabria). Zephyrus 60: 43-58.

Ambrústolo, P.; Zubimendi, M.A.; Ciampagna, M.L. \& TROLA, V. 2011: Alero El Oriental: evidencias de las primeras ocupaciones de la costa norte de Santa Cruz (Patagonia, Argentina). Werkén 14(1): 9-22.

Beretta, J.M.; Corinaldessi, L. \& Castro, A. 2011: Recursos marinos vs. recursos terrestres: análisis arqueofaunístico en el sitio cueva del negro, costa norte de Santa Cruz. Arqueología 17: 137-160.

Beretta, M.; Zubimendi, M.A.; Ciampagna, M.; Ambrústolo, P. \& Castro, A. 2013: Puntas de arpón en la costa norte de Santa Cruz: primeros estudios de piezas recuperadas en estratigrafía en el sitio Cueva del Negro. Magallania 41(1): 211-221.

BINFORD, L.R. 1981: Bones: ancient men and modern myths. Academic Press, New York.
Castellanos, Z.A. 1956: Catálogo de los poliplacóforos argentinos y de aguas vecinas al estrecho de Magallanes. Revista del Museo de la Universidad de La Plata (Nueva serie). Sección Zoología 6: 465-486.

Castellanos, Z.A. \& Landoni, N. 1988: Catálogo descriptivo de la malacofauna marina magallánica 2. Archigastropoda. Comisión de Investigaciones Científicas de la Provincia de Buenos Aires.

Castro, A.S.; Moreno, J.E.; Andolfo, M.; Giménez, R.; Peña, C.; Mazzitelli, L.; Zubimendi, M.A. \& AmBRÚstolo, P. 2003: Análisis distribucionales en la costa de Santa Cruz (Patagonia Argentina): alcances y resultados. Magallania 31: 69-94.

Carcelles, A.R. 1950: Catálogo de los moluscos marinos de la Patagonia. Ministerio de Obras Públicas de la Nación, Administración General de Parques Nacionales y Turismo.

Carcelles, A.R. \& Williamson, S.J. 1951: Catálogo de los moluscos marinos de la Provincia Magallánica. Revista del Instituto Nacional de Investigación de las Ciencias Naturales. Ciencias Zoológicas, Tomo II (5): 225-382.

Claassen, C. 1998: Shells. Cambridge Manuals in Archaeology. Cambridge University Press, New York.

Codignotto, J.O.; Kокот, R.R. \& Marcomini, S.C. 1992: Neotectonism and sea-level changes in the coastal zone of Argentina. Journal of Coastal Research: 125-133.

ERlandson, J.M. \& Rick, T.C. 2008: Archaeology, marine ecology, and human impacts on marine ecosystems. In: Rick, T.C. \& Erlandson, J.M. (eds.): Human Impacts on Ancient Marine Ecosystems: A Global Perspective: 1-19. University of California Press, Berkeley.

ForCelli, D.O. 2000: Moluscos magallánicos: guía de los moluscos de la Patagonia y del sur de Chile. Vázquez Mazzini Editores, Buenos Aires.

González Bonorino, G.; Bujalesky, G.; Colombo, F. \& FERrERo, M. 1999: Holocene coastal paleoenvironments in Atlantic Patagonia, Argentina. Journal of South American Earth Sciences 12(3): 325-331.

GordiLlo, S. 2007: Análisis tafonómico de quitones (Polyplacophora: Mollusca) holocenos de Tierra del Fuego, Argentina. Ameghiniana 44(2): 407-416.

GutiérRez Zugasti, I. 2008: La explotación de moluscos y otros recursos litorales en la región cantábrica durante el Pleistoceno final y el Holoceno inicial. Tesis doctoral Departamento de Ciencias Históricas. Universidad de Cantabria.

Hammond, H. 2013: Propuesta metodológica para el estudio de conjuntos malacológicos de sitios concheros: su aplicación en la costa norte de Santa Cruz (Patagonia Argentina). La Zaranda de Ideas 9(2): 77-102. 
- 2015: Sitios concheros en la costa norte de Santa Cruz: su estructura arqueológica y variabilidad espacial en cazadores recolectores patagónicos. Tesis doctoral Facultad de Cs. Naturales y Museo, Universidad Nacional de La Plata.

Hammond, H. \& Zilio, L. 2016: Experimentación del proceso de recolección de moluscos de la especie $\mathrm{Na}$ cella magellanica y sus implicancias en el análisis de muestras arqueomalacológicas. Comechingonia. Revista de Arqueología 20(2): 265-290.

Hammond, H.; Zubimendi, M.A. \& Zilio, L. 2013: Composición de concheros y uso del espacio: aproximaciones al paisaje arqueológico costero en Punta Medanosa. Anuario de Arqueología 5: 67-84.

Iantanos, N. 2004: Dinámica sedimentaria de la Ría Deseado, Provincia de Santa Cruz. Tesis doctoral Universidad Nacional de la Patagonia Austral.

Lasta, M.L.; Ciocco, N.F.; Bremec, C. \& Roux, A. 1998: Moluscos bivalvos y gasterópodos. El mar argentino y sus recursos pesqueros 2: 115-142.

Mannino, M. \& Thomas, K. 2002: Depletion of a resource? The impact of prehistoric human foraging on intertidal mollusc communities and its significance for human settlement, mobility and dispersal. World Archaeology 33(3): 452-474.

Morales, M.; Barberena, R.; Belardi, J.B.; Borrero, L.; Cortegoso, V.; Durán, V.; Guerci, A.; GoÑI, R.; Gil, A.; Neme, G.; Yacobaccio, H. \& Zárate, M. 2009: Reviewing human environment interactions in arid regions of southern South America during the past 3000 years. Palaeogeography, Palaeoclimatology, Palaeoecology 281(3): 283-295.

Moreno, E. 2008: Arqueología y etnohistoria de la Costa Patagónica Central en el Holoceno Tardío. Fondo Editorial Provincial, Secretaría de Cultura del Chubut.

Moreno, E.; Zangrando, A.F.; Tessone, A.; Castro, A.S. \& Panarello, H. 2011: Isótopos estables, fauna y tecnología en el estudio de los cazadores-recolectores de la costa norte de Santa Cruz. Magallania 39(1): 265-276.

MoReno Nuño, R. 1994: Análisis arqueomalacológicos en la Península ibérica. Contribución metodológica y biocultural. Tesis doctoral Universidad Autónoma de Madrid, Madrid.

NúÑEz Cortés, C. \& NARovsky, T. 1997: Cien caracoles argentinos. Editorial Albatros, Buenos Aires.

Orquera, L.A. \& Piana, E.L. 1999: Arqueología de la región del Canal Beagle: Tierra del Fuego, República Argentina. Sociedad Argentina de Antropología, Buenos Aires.

- 2000: Composición de conchales de la costa del Canal Beagle (Tierra del Fuego, República Argentina)
-Primera Parte-. Relaciones de la Sociedad Argentina de Antropología 25: 249-274.

Rostami, K.; Peltier, W.R. \& Mangini, A. 2000: Quaternary marine terraces, sea-level changes and uplift history of Patagonia, Argentina: comparisons with predictions of the ICE-4G (VM2) model of the global process of glacial isostatic adjustment. Quaternary Science Reviews 19(14): 1495-1525.

SteIN, J.K. 1987: Deposits for archaeologyst. In: Schiffer, M.B. (ed.): Advances in Archaeologycal Method and Theory 11: 337-395. Academic Press, San Diego.

THAKAR, H.B. 2011: Intensification of shellfish exploitation: Evidence of species-specific deviation from traditional expectations. Journal of Archaeological Science 38(10): 2596-2605.

VERDÚN,E. 2014: Application of biometric analyses on shell middens of hunter-fisher-gatherer societies of Tierra del Fuego (Argentina). Archaeofauna 23: 221-236.

YeSNER, D.R. 1980: Maritime hunter-gatherers: ecology and prehistory. Current Anthropology 21(6): 727-750.

Zaixso, H.E. \& Boraso De Zaixso, A. 2013: Bentos. En: Plan de manejo Reserva Provincial Ría Deseado: 3138. Consejo Agrario Provincial, Santa Cruz.

ZANGRANDO, A.F. 2009: Historia evolutiva y subsistencia de cazadores-recolectores marítimos de Tierra del Fuego. Sociedad Argentina de Antropología.

ZiLIO, L. 2015: Prácticas mortuorias en la costa norte de Santa Cruz: arqueología de sociedades cazadoras recolectoras en paisajes costeros de la Patagonia argentina. Tesis doctoral Facultad de Cs. Naturales y Museo. Universidad Nacional de La Plata.

Zilio, L.; Gordón, F.; Béguelin, M. \& Castro, A.S. 2014: Paleodietas humanas en el sur del Golfo San Jorge (provincia de Santa Cruz) a partir del análisis de isótopos estables. Revista Argentina de Antropología Biológica 16: 51-64.

ZuBImENDI, M.A. 2012: La variabilidad del registro arqueomalacológico en la costa norte de Santa Cruz (Patagonia argentina): resultados exploratorios a partir de estudios estratigráficos. Intersecciones en Antropología 13(2): 359-375.

Zubimendi, M.A.; Ambrústolo, P.; Zilio, L. \& Castro, A. 2015: Continuity and discontinuity in the human use of the north coast of Santa Cruz (Patagonia Argentina) through its radiocarbon record. Quaternary International 356: 127-146.

Zubimendi, M.A. \& Hammond, H. 2009: Análisis de los restos malacológicos en el sitio Los Albatros, Bahía del Oso Marino (Santa Cruz). En: Salemme, M.; Santiago, F.; Álvarez, M.; Piana, E.; Vázquez M. \& Mansur, E. (eds.): Arqueología de la Patagonia: una mirada desde el último confin: 865-877. Utopías, Ushuaia. 